\title{
Chapter 6 Supporting beginning teachers with lesson planning
}

\author{
Gareth Bates, Ralph Littler, Morag Findlay and Saima Salehjee
}

\section{Introduction}

The planning and teaching of lessons are integral to the role of a teacher. In our experience as teacher educators and school-based mentors, a series of lessons which are carefully planned and clearly articulated by the teacher are the ones that are most successful for pupils' learning. Our experience aligns with the quote allegedly by Benjamin Franklin, 'If you fail to plan, you are planning to fail.' However, as experienced teachers, we know that not all lessons go according to plan. As a mentor, you need to be resilient and accepting of the fact that a beginning teacher could 'fail' due to insufficient understanding of the long-term effect of planning on pupils' learning. As a consequence, you need to have well developed strategies in place to support a beginning teacher to cultivate understanding of advanced practices of lesson planning.

This chapter addresses issues that a beginning teacher might have with lesson planning. It draws on strands from Chapter 4 on reflective practices by adapting Kolb's learning cycle (Kolb, 1984) to the planning process, exploring potential strategies that you can implement to support a beginning teacher. Using Daloz's mentoring model (Daloz, 2012) (see Chapter 1) and Rogoff's (1995) adapted model, this chapter explores when and how you can support and challenge a beginning teacher to become autonomous in planning for pupils' learning. Additionally, using perspectives from cognitive psychology on learning, the chapter frames how you can facilitate a beginning teacher to plan lessons that support a long-term curriculum plan.

\section{Objectives}

At the end of this chapter, you should be able to:

1. Use Kolb's experiential learning cycle to reflect on supporting a beginning teacher to plan lessons; 
2. Support a beginning teacher's transition from being able to plan sections of lessons (micro-planning), to single three-part lessons for a whole class, and finally to plan differentiated long-term curriculum plans - using Rogoff's 'apprenticeship', 'guided participation' and 'participatory appropriation' developmental planes.

\section{Lesson planning as a reflective process}

Effective lesson planning is a reflective process. You could use Kolb's (1984) 'experiential learning' theory as a framework to explore how you can best support a beginning teacher to plan lessons for pupils' learning. Kolb (1984) described the idealised learning cycle (Figure 6.1, see also Chapter 4, ppxx on using Kolb's learning cycle to support a beginning teacher to write self-reflective accounts) as a recursive process where the learner, in this case a beginning teacher, experiences (Concrete Experience (CE)), reflects (Reflective Observation (RO)), thinks (Abstract Conceptualisation (AC)) and then acts (Active Experimentation (AE)). As an example, a beginning science teacher's direct experience (CE) is teaching a lesson to a class. The next lesson for the same class is planned by them after reflecting (RO) on how the lesson went, which leads to some development or organisation of resources (AC), which are then deployed in the next lesson (AE).

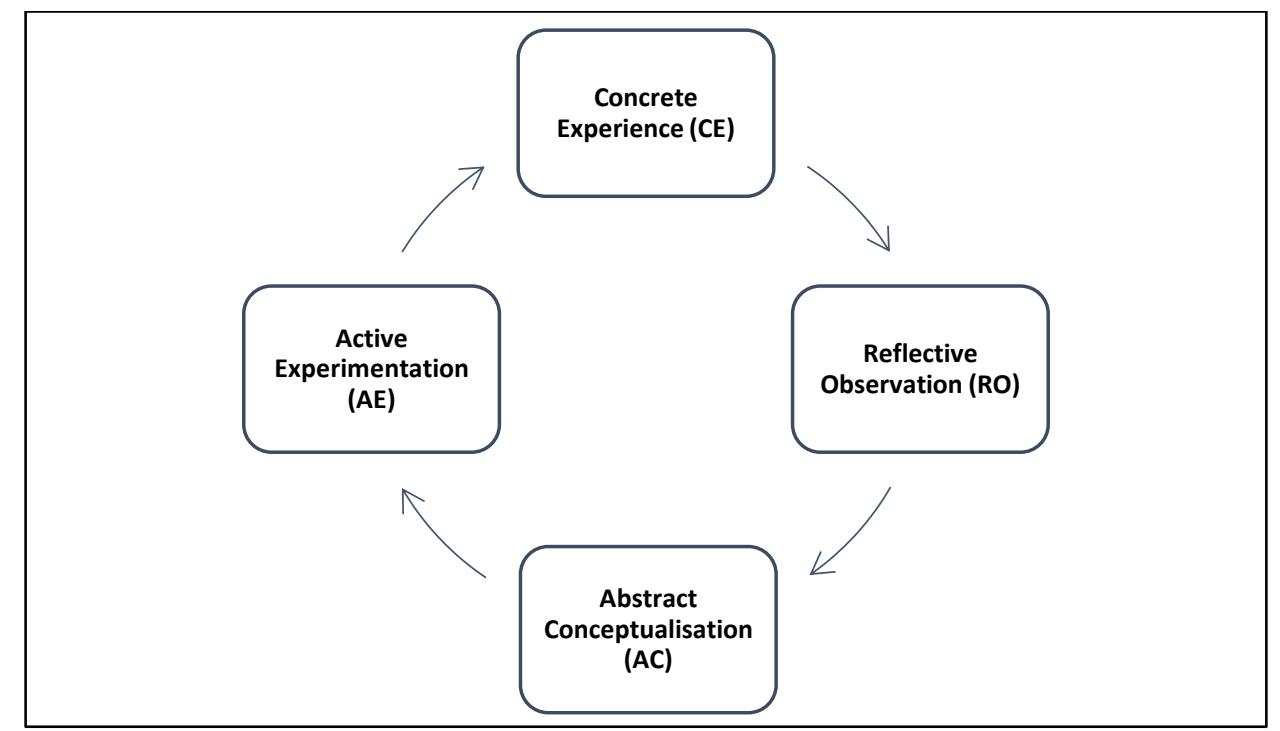

Figure 6.1 Kolb's experiential learning cycle (Kolb, 1984).

Task 6.1 asks you to use Kolb's (1984) experiential learning cycle to reflect on your mentoring approaches to support a beginning teacher in lesson planning. 
Task 6.1 Mentoring to support lesson planning by using Kolb's experiential learning cycle

Address the questions below:

1. At what point in Kolb's cycle should you be asking for a lesson plan or lesson plans from a beginning teacher? and Why?

2. If you request lesson plan(s) from a beginning teacher in advance of teaching a lesson, how far in advance?

3. What feedback should you be giving to the beginning teacher before they teach the lesson?

4. How far in advance should you be giving feedback on a lesson plan and/or series of lesson plans to the beginning teacher?

5. Once you have observed a lesson, what feedback should you be giving to the beginning teacher that can support them to plan for the next lesson and/or series of lessons?

6. How will you incorporate the use of Kolb's learning cycle in the beginning teacher's planning routine?

You will notice that your answers to Task 6.1 differ as a beginning teacher gains more experienced in planning lessons over time. Hence, while using Kolb's cycle, you need to acknowledge the prior experiences and developmental needs of the beginning teacher. Different feedback could be given about lesson plans to a beginning teacher at different stages of their development, for example:

- When a beginning teacher is co-planning with you and/or an experienced teacher, then your feedback on lesson plans prior to the lesson should be focused on procedural errors such as practical timing and choice of activities

- During the initial stages of lesson planning, we believe that you should let a beginning teacher try out some of their self-planned approaches to teaching. But be mindful, if you see that they have planned a new strategy that could possibly fail in practice, then tell them why they need to modify/change it and offer suggestions

- Once a beginning teacher has started to plan full lessons more independently then you should be constructive in your feedback on lesson planning; for example, you can talk about the relevance of pedagogical theories and assessments and curriculum for planning a lesson to enhance pupils' learning 
- Throughout the feedback process you should be encouraging a beginning teacher to reflect on their pre-lesson planning, teaching and post-lesson planning, consequently facilitating Kolb's experiential learning cycle.

In addition to the above points, your support to a beginning teacher during the course of their developmental journey, should be aimed at the development of pupils' long-term learning. However, the constraints of a school's timetable, wider curricula, the demands of the standardised curricula (such as the National Curriculum for England) and examination constraints, limit a beginning teacher to planning learning for their pupils within a short number of lessons. Before reading further on supporting a beginning teacher to gradually develop their planning skills to plan for pupils long-term learning, Task 6.2 asks you to reflect on the process of planning that you have established (or intend to establish) to support a beginning teacher you are mentoring.

\section{Task 6.2 Mentor's self-reflection on supporting a beginning teacher to plan a single} and/or series of lessons

Reflect on the following questions:

1. How do you, as a mentor, support a beginning teacher to plan lessons?

2. Do you use any particular template and/or reflective model to assist a beginning teacher?

3. What resources do you provide a beginning teacher to use for planning (such as units of work, sample lesson plans et cetera)?

4. What institutional and curriculum-based influences (positive and/or negative), do you think can impact the way in which a beginning teacher plans for long-term benefits to pupil's learning?

5. Do you recommend single lesson plans and/or long-term plans? and Why?

6. What mentoring methods could you employ to support a beginning teacher in planning lessons aiming for pupils' learning?

\section{Supporting a beginning teacher's developmental journey of planning}

This section of the chapter provides some mentoring strategies to support a beginning teacher to plan lessons at different stages of their development towards becoming an autonomous teacher. We use Rogoff's (1995) three planes of development which a beginning teacher generally goes through in their journey. A short description of these three planes, along with 
its resemblance to Katz's (1995) stages of development (a detailed description on Katz (1995) four-stages of development is given in Chapter 1) are:

1. Apprenticeship plane, this stage is typically at the start of a beginning teacher's placement in your school. It resembles Katz's (1995) survival stage and exhibits some signs of the consolidation stage. In this plane a beginning teacher is contributing to planning some sections of the lessons

2. Guided participation, this plane of development covers a beginning teacher's development from Katz's consolidation stage to the renewal stage, where they are given responsibility to plan full lessons for different classes

3. Participatory appropriation, at the end of this stage, a beginning science teacher should be autonomously planning series of lessons with an aim to plan for a sequence of learning rather than focusing on a short number of lessons of learning gains for all the pupils. This plane resembles Katz's maturation stage.

The next section presents the three planes and some possible mentoring suggestions that you can employ to support a beginning teacher's developmental journey of planning effective lessons. The sequence of mentoring suggestions covering a specific developmental plane are not fixed. These suggestions are simply some guidelines for you to adopt/adapt according to the needs of a beginning teacher you are mentoring.

\section{Apprenticeship plane}

At this early stage of development, a beginning teacher needs support in settling in. Using Daloz's (2012) model of mentoring, in order to achieve 'growth' in learning, you need to give a beginning teacher high support and high challenge. In order to give high support at this stage, we suggest that you allow the beginning teacher to observe experienced teachers planning, and micro-plan some of the lessons with the classes you intend them to co-teach.

This apprenticeship plane is a modelling phase, where you share some example lesson plans as models of your own practice and discuss ideas on how to plan effective lessons. During these discussions, you may want to emphasises the importance of planning and indicate to the beginning teacher that, at the start of their teaching career, they may observe experienced teachers who 'just know' how much to put into each part of a lesson and can effectively and quickly change/adopt their planning according to the need of pupils. This is probably because 
they have planned just about every conceivable situation, and have a better control on changing strategies as they go along, either in planning one or a series of lessons. In addition, your discussions could involve sharing your experiences of altering your lesson plans on a regular basis, with a focus on the idea that one planned lesson or a series of lessons - for a particular age group of pupils - is not a finished article. Rather, teachers are required to continually refine and adapt their plans according to the teaching and learning circumstances, such as school/classroom context and pupils' learning needs.

After these initial discussions with a beginning teacher you could consider how your colleagues can have an input into supporting the development of the beginning teacher to plan effective lessons. To initiate this involvement, you could arrange for a beginning teacher to observe an experienced teacher's lesson(s) (ideally a science teacher, if there is more than one science teacher in your school). It is important to involve experienced science teachers at this early stage of development, because it is unlikely that a beginning teacher will only be teaching lessons solely to the classes you normally teach. Before arranging these observations, you need to ensure the best support for the beginning teacher. Therefore, think about the following:

- What are the strengths and expertise of the experienced science (or non-science) teacher that can support the beginning teacher?

- What could the beginning teacher learn from them?

- What information would you give to the teacher about the beginning teacher?

- What support would you like the teacher to provide them?

After considering the above points, select an experienced teacher who can support the beginning teacher in planning effective lessons. Task 6.3 asks you to arrange lesson observations of an experienced teacher for a beginning teacher which provide opportunities for the beginning teacher to learn about the importance of effective planning for their teaching practices. 
Task 6.3 Mentoring to support effective planning through arranging lesson observations of experienced teachers for a beginning teacher

1. Prior to arranging an observation of an experienced teacher's lesson (ideally a science teacher), encourage the beginning teacher to list some questions that they would like to ask the experienced teacher about planning, such as what planning of the lesson or a series of lessons have they undertaken and why? What will they do if the planning does not go according to plan? et cetera

2. During the lesson observation, ask the beginning teacher to make notes on the ways the experienced teacher uses planned activities to benefit pupils' learning. What was good about it? What teaching strategies did the experienced teacher use in the class and how did they detail these teaching strategies in their lesson plans?

3. Discuss these observational notes in your next weekly mentoring meeting with the beginning teacher.

[You might arrange more than one lesson observations for the beginning teacher. In this case, repeat the above steps for the selected experienced teacher or teachers].

During this stage, in addition to observing and evaluating an experienced teacher, you can support a beginning teacher with micro-planning. Micro-planning involves a beginning teacher planning certain parts of a lesson, for instance, preparing for lesson starters, mini-plenaries, experiments, et cetera. Discussions on micro-planning can then support the beginning teacher to co-plan a complete lesson with you and/or with other experienced teachers. As they grow in confidence, the beginning teacher can start planning activities for a co-planned lesson and you can provide feedback on these planned activities. This co-planning of lessons can start from the apprenticeship plane and can be continued to the advanced participatory appropriation plane of development. The kind, manner and level of mentoring support in co-planning lessons will differ between the beginning (apprenticeship) and advanced (participatory appropriation) planes of development.

Guided participation plane: Understanding the science curriculum to plan learning outcomes and key questions

Using Daloz's (2012) model, at this plane of development, the high challenge for a beginning teacher is from the accountability and responsibility they have for planning full lessons for 
different classes. Therefore, initially, you can provide high support through co-planning of full lessons. Ideally a co-planned lesson should be a contemporaneous account of a face-to-face conversation about the lesson. Therefore, at this stage, co-planning should involve discussion about effective planning with a focus on pupils' learning progression, i.e. emphasising what pupils are expected to have learned at the end of the lesson, indicating one or more learning expectations recommended under the specific unit of work.

In this chapter, the term 'unit of work' is used to indicate different units or blocks of work that originate from the government's approved science curriculum. In England, these units of work can be found in the relevant curriculum documents, for example, DfE (2013) for Key Stage 3 (age group 11-14) and DfE (2014) for Key Stage 4 (age group 14-16). As mentioned in the introduction to this book, you might need to adopt/adapt these curriculum documents according to the curriculum requirements of the country/examination boards/school in which you are working. A list of some units of work is also presented in Appendix 10.1 of Chapter 10, which can be shared with the beginning teacher for guidance.

This co-planning support is part of the early development of a beginning teacher, 'however, it is most beneficial when it is ongoing, as the demands and expectations of the lesson plan become increasingly pupil-centred' (Binney, Barrett, Green, Pocknell \& Smart, 2019, p.167). Depending on the developmental stage and needs of a beginning teacher, your support with guided co-planning can vary; therefore, the steps outlined in this section are not absolute and can be adopted/adapted respectively.

Some mentoring support you could provide to a beginning teacher to continue with the co-planning associated discussions on planning a whole lesson is considered next. Some different and more advanced approaches to support a beginning teacher to plan lessons are also covered in other chapters of the book, for example, Chapter 15. You can choose and select a mentoring approach according to the needs of a beginning teacher and focus of your support.

\section{Learning outcomes and pupils learning}

An understanding of a unit of work is an ongoing process for a beginning teacher, for which you can provide support to plan learning outcomes that support pupils' learning identified in the unit of work. Before supporting a beginning teacher to write learning outcomes, you need to share some example learning outcomes with them. You could then support the beginning teacher to write learning outcomes for lesson plans they intend to teach. This provides a source of evidence that they can use to demonstrate 'what learning is intended?' before the lesson and 
'what outcomes have achieved (or not)?' after the lesson. While supporting the beginning teacher to write learning outcomes, it is noted that most beginning teachers often find it easy to identify the activities pupils will complete during a lesson, but they find difficulty identifying the learning which will take place. To this end, Task 6.4 asks you to support a beginning teacher by sharing some example learning outcomes.

\section{Task 6.4 Supporting a beginning teacher to identify pupils learning}

Undertake the following steps to support a beginning teacher to identify learning expected by pupils from each of the planned learning outcomes:

1. Ask the beginning teacher to look at Table 6.1, which indicates five-example learning outcomes (LO1 - LO5) in the first column; for the 'electricity' unit of work, specifically on 'current, resistance and voltage relationships for different circuit elements; including their graphical representations' (DfE, 2014, p. 15). In the second column the beginning teacher is asked to write about the relevance of each of the six learning outcomes in achieving exected learning for the given aspect of the unit of work

2. Next encourage the beginning teacher to discuss Table 6.1 with you for further guidance

3. These steps could be followed in the similar way for other aspects of the same unit of work (or other units of work) that you think are appropriate to share. 
Table 6.1 Learning outcomes and pupils learning.

\begin{tabular}{|c|c|}
\hline $\begin{array}{l}\text { Learning outcomes (LO) } \\
\text { for } \\
\text { 'Exploring current, resistance and voltage relationships } \\
\text { for different circuit elements; including their graphical } \\
\text { representations' (DfE, 2014, p. 15). }\end{array}$ & $\begin{array}{l}\text { The relevance of the learning outcomes (LO) in } \\
\text { achieving the expected pupils' learning } \\
\text { for } \\
\text { 'Exploring current, resistance and voltage } \\
\text { relationships for different circuit elements; } \\
\text { including their graphical representations' (DfE, } \\
\text { 2014, p. 15). }\end{array}$ \\
\hline $\begin{array}{l}\text { LO1 Set up a series electrical circuit to measure the } \\
\text { current through a resistor and the voltage across it as } \\
\text { the current in the circuit is varied }\end{array}$ & \\
\hline $\begin{array}{l}\text { LO2 Record the results in a table and calculate the } \\
\text { ratio of the voltage across the resistor to the current } \\
\text { through the resistor }\end{array}$ & \\
\hline $\begin{array}{l}\text { LO3 State that the value of voltage divided by current } \\
\text { is approximately constant }\end{array}$ & \\
\hline $\begin{array}{l}\text { LO4 State the formula for Ohm's law and explain the } \\
\text { meaning of the symbols used }\end{array}$ & \\
\hline LO5 Plot a graph of voltage against current & \\
\hline $\begin{array}{l}\text { LO6 State that the resultant straight-line graph shows } \\
\text { that the voltage across a resistor is directly proportional } \\
\text { to the current through it. }\end{array}$ & \\
\hline
\end{tabular}

2.Learning outcomes and key questions

After supporting a beginning teacher to discuss learning outcomes and associated pupils' learning expectations identified in the science curriculum's units of work, you can then support them to use key questions characterising the course of the lesson. Key questions can give the skeleton of the lesson or provide a series of waypoints which a beginning teacher has to reach to organise the lesson. How the lesson progresses between the waypoints depends on the interaction between the beginning teacher and the class. The key questions are often linked to learning outcomes. In addition to the scripted key questions, a beginning teacher and/or the pupils could ask many spontaneous questions as the lesson progresses (Chapter 11). Task 6.5 looks at a beginning teacher writing key questions for the learning outcomes presented in Table 6.1. Task 6.6 then focuses on mentoring steps to support the beginning teacher to embed key questions in their lesson planning. 


\section{Task 6.5 Writing key questions to accomplish a smooth progression of a lesson}

Ask the beginning teacher to follow these steps:

1. Look back at Task 6.4 (Table 6.1) and write some key questions for each learning outcome.

[You could use Table 6.1 to focus on learning outcomes and pupils learning from a different unit of work and ask the beginning teacher to write key questions accordingly.]

2. What question(s) would they ask in an exit pass at the end of the lesson?

3. Compare the beginning teacher's key questions with the possible example key questions presented in Table 6.2 .

Table 6.2 Possible key questions (KQ) for the learning outcomes (LO) presented in Table 6.1.

LO1: KQ1 How can pupils design an electrical circuit to measure the current through a resistor and the voltage across it?

LO2: KQ2 Looking at the results table, what can pupils tell about the value of the voltage across the resistor as the current through it increases?

LO3:KQ3 What happens to the voltage across the resistor when the current through it doubles, et cetera?

LO4: KQ4 Can pupils describe the relationship between the current through the resistor and the voltage across it?

LO5: KQ5 What sort of line can pupils draw on the graph? (straight-line or curve of best fit)

LO6: KQ6 What is the relationship between the current and the voltage for a resistor?

LO4/6: KQ4/6 What is the relationship between the voltage across a resistor and the current through it? 
Task 6.6 Embedding key questions as part of a beginning teacher's planning to strengthen pupils' learning

After completing Task 6.5 with a beginning teacher, follow the steps below:

1. Ask the beginning teacher to plan a series of lessons within a specific unit of work, focusing on the use key questions. Review the lesson plans and ask the beginning teacher to justify their questioning choices to evaluate pupils' progress

2. Following the series of lessons, support the beginning teacher to evaluate the effectiveness of their key questioning technique using pupils' feedback as a means to assess pupils' progress formatively and how they can improve the effectiveness of this strategy further

3. Encourage the beginning teacher to differentiate the above questions catering for all the pupils (some examples are provided in Table 6.5).

Once the beginning teacher masters the use of key questioning, you could refer them to Chapter 11, which introduces other ways of planning rich questioning to develop classroom dialogue and building confidence among pupils. See also Chapter 15 (pxx) which suggests ways to support a beginning teacher to construct learning outcomes by embedding scientific literacy approaches to learning using a range of verbs (Table 15.1), and Chapter 18 to promote enrichment activities.

\section{Guided participation plane (continued): Three-part lesson plan}

At this stage of guided participation, some full lessons for a specific class of pupils could be planned over a period of time - a week or two, which could later build up into series of lessons comprising of a complete (or some aspects) unit of work. At this stage of guidance, you could use a three-part lesson plan design (comprising a lesson starter, the main body of the lessons and the consolidation parts) to support a beginning teacher to plan a whole class lesson under your guidance (Fautley \& Savage, 2013). The beginning teacher needs to understand that the boundaries between start (lesson starter), middle (main body) and end (consolidation) of the three-part lesson plan should be fluid, to allow ease of flow between the three-parts, to present a whole lesson picture rather than three isolated parts of a lesson. 
Table 6.3 presents a co-planned lesson plan for one of the lessons in a unit of work on 'electricity'. The learning outcomes (Table 6.1) and key questions (Table 6.2) are revisited in this lesson plan.

Table 6.3 A lesson plan.

Class: $3 \mathrm{~A}$

Year group: Year 9 / Secondary 2

Date: XXXX

Lesson number: $\mathrm{XX}$

Unit of work: 'Electricity'

Topic: 'Current, resistance, voltage and Ohm's law', specifically on 'exploring current, resistance and voltage relationships for different circuit elements; including their graphical representations' (DfE, 2014, p. 15).

\section{Learning outcomes (LO)}

All pupils will be able to:

LO1 Set up a series electrical circuit to measure the current through a resistor and the voltage across it as the current in the circuit is varied

LO2 Record the results in a table and calculate the ratio of the voltage across the resistor to the current through the resistor

LO3 State that the value of voltage divided by current is approximately constant

LO4 State the formula for Ohm's law and explain the meaning of the symbols used.

Some pupils will be able to:

LO5 plot a graph of voltage against current

LO6 state that the resultant straight-line graph shows that the voltage across a resistor is directly proportional to the current through it.

\begin{tabular}{|l|l|l|l|}
\hline Activity & Time & Teacher activities & Pupils activities \\
& & & \\
\hline Part-one: Start & & \\
\hline
\end{tabular}




\begin{tabular}{|c|c|c|c|}
\hline Lesson starter & Five-minutes & $\begin{array}{l}\text { What would be different if } \\
\text { there was a power cut right } \\
\text { now? } \\
\text { Why is electricity important? }\end{array}$ & $\begin{array}{l}\text { Pupils write down two or } \\
\text { three things that would be } \\
\text { different in a power cut. } \\
\text { Brief class discussion. }\end{array}$ \\
\hline \multicolumn{4}{|l|}{ Part-two: Main body } \\
\hline $\begin{array}{ll}\text { Designing the } & \text { the } \\
\text { investigation } & \end{array}$ & Ten-minutes & $\begin{array}{l}\text { KQ1 How can you design an } \\
\text { electrical circuit to measure } \\
\text { the current through a resistor } \\
\text { and the voltage across it? } \\
\text { Eliciting ideas from the pupils } \\
\text { and mark the investigation pro } \\
\text { forma (Appendix 6.1) to } \\
\text { assess their understanding and } \\
\text { scientific skills. } \\
\text { Guiding pupils to include all } \\
\text { relevant data in the table. }\end{array}$ & $\begin{array}{l}\text { Think-pair-share activities } \\
\text { to develop the circuit } \\
\text { Designing a table for results } \\
\text { Draw a circuit diagram and } \\
\text { add the table headings in the } \\
\text { investigation pro forma in } \\
\text { Appendix 6.1. }\end{array}$ \\
\hline $\begin{array}{l}\text { Carrying out the } \\
\text { investigation }\end{array}$ & Twenty- minutes & $\begin{array}{l}\text { Giving instructions about } \\
\text { collecting the equipment } \\
\text { Monitoring progress by } \\
\text { patrolling the laboratory } \\
\text { Interacting with groups of } \\
\text { pupils and assessing their } \\
\text { experimental skills. } \\
\text { KQ2 Looking at the results } \\
\text { table, what can pupils tell } \\
\text { about the value of the voltage } \\
\text { across the resistor as the } \\
\text { current through it increases? } \\
\text { Asking questions to assess and } \\
\text { guide progress } \\
\text { KQ3 What happens to the } \\
\text { voltage across the resistor }\end{array}$ & $\begin{array}{l}\text { Working in groups } \\
\text { Setting up the circuit } \\
\text { Recording results } \\
\text { Looking for the relationship } \\
\text { between the variables in } \\
\text { tabular or graphical form as } \\
\text { appropriate (Appendix 6.1) } \\
\text { Tidying up equipment }\end{array}$ \\
\hline
\end{tabular}




\begin{tabular}{|c|c|c|c|}
\hline & & $\begin{array}{l}\text { when the current through it } \\
\text { doubles, et cetera? } \\
\text { KQ4 Can pupils describe the } \\
\text { relationship between the } \\
\text { current through the resistor } \\
\text { and the voltage across it? } \\
\text { Asking quick finishers to plot } \\
\text { a graph of their results } \\
\text { KQ5 What sort of line can } \\
\text { pupils draw on the graph? } \\
\text { (Straight-line or curve of best } \\
\text { fit. } \\
\text { KQ6 What is the relationship } \\
\text { between the current and the } \\
\text { voltage for a resistor? }\end{array}$ & \\
\hline $\begin{array}{l}\text { Part-thr } \\
\text { Exit pass }\end{array}$ & $\begin{array}{l}\text { ation } \\
\text { Vhat is one th }\end{array}$ & arned today and one thing you we & int to find out about? \\
\hline Plenary & 10 minutes & $\begin{array}{l}\text { Discussing results } \\
\text { Eliciting relationship from } \\
\text { pupils both as a verbal } \\
\text { relationship and as a formula } \\
\text { KQ4/6 What is the } \\
\text { relationship between the } \\
\text { voltage across a resistor and } \\
\text { the current through it? See } \\
\text { also KQ2, KQ3 and KQ5. } \\
\text { Giving instructions for exit } \\
\text { pass using pencil and } \\
\text { paper/electronic devices } \\
\text { Dismissing pupils }\end{array}$ & $\begin{array}{l}\text { Working individually, in } \\
\text { pairs, practical groups or as a } \\
\text { class to reach conclusion } \\
\text { Recording conclusion and } \\
\text { formula on exit passes }\end{array}$ \\
\hline $\begin{array}{l}\text { Links to } \\
\text { - } \text { Hon } \\
\text { - App }\end{array}$ & $\begin{array}{l}\text { ng lesson(s) } \\
\text { be set after tl } \\
\text { w to solve pr }\end{array}$ & n & \\
\hline
\end{tabular}


- Investigate what happens when the temperature of a resistor/component changes.

A brief description on the three-part lesson plan in Table 6.3 is as follows:

1.Part-one: Start

The first part of the lesson plan could include a starter activity to engage and challenge pupils at the start of the lesson. You can support the beginning teacher to plan lesson starters by:

- Asking them to come up with three lesson starters from different sources such as textbooks, internet search, et cetera. Encourage the beginning teacher to plan the first lesson starter linking to the everyday use of Ohm's law, second starter from the news, third starter, some questions that can evaluate what pupils' misconceptions were gained from the previous lesson(s)

- Ask the beginning teacher to plan the timings of the starters. This should not be longer than $10 \%$ of the lesson time. This will support them in setting the pace of starter activity

- Encourage the beginning teacher to plan for rewards for pupils who effectively complete the starter activity in a given time

- Finally, discuss the benefits and drawbacks of the three lesson starters, the suitability of them with the planned learning outcomes and, together with the beginning teacher, agree on one of the lesson starters that will be used for the upcoming lessons on 'electricity'.

\section{Part-two: Main body}

This section looks at pupil and teacher activities which can be outlined according to the planned key questions in Table 6.2. Through discussions, you can support the beginning teacher to plan some activities according to the possible key questions.

Next, you can advise the beginning teacher to plan two to three specific mini-sections of part-two (main body). Some ideas for mini-sections could be:

- Problem-solving activities, such as allowing pupils to solve problems in building electrical circuits

- Skill development, such as after a series of teacher demonstrations the class have the task of explaining the relationships between 'current, resistance and voltage', using existing resources and/or resources pupils make for themselves 
- Writing-based activities such as pupils critiquing the laboratory report of peers prior to producing their own.

The example lesson plan on 'current, resistance, voltage and Ohm's law', under the unit of work 'electricity' (Table 6.3) includes mini-sections, such as problem-solving (such as thinkpair-share activities to develop electrical circuit), skill development (such as setting up the circuit), and writing-based activities (such as pupils writing down two or three things that would be different in a power cut) within the two broad divisions of 'designing the investigation' for ten-minutes and 'carrying out the investigation' for twenty-minutes.

Some other suggestions you could make to the beginning teacher at this plane of development could be to plan:

- Individual, peer or group work resources and the physical environment

- Teacher's activities to support pupils' activities

- An introduction to differentiating teacher's activities to support the learning of all pupils (see also participatory appropriation plane section below)

- Time allocation accounting for classroom routines (such as the time it will take to set up an investigation, carrying out the investigation and clearing away)

- Formative styled assessment procedures.

Some examples to these recommendations can be seen in Table 6.3.

\section{Part-three: Consolidation}

The plenary forms the third section of the three-part lesson plan. It completes the lesson, consolidates the lesson for pupils and the beginning teacher and provides planning avenues for the next lesson. You can support the beginning teacher to plan some plenary questions that consolidate the learning of pupils and enable them to signpost learning for the next lesson or a series of lessons. You can support the beginning teacher to plan plenaries, for example on 'electricity' (focusing on 'current, resistance, voltage and Ohm's law'), by:

- Asking the beginning teacher to come up with some plenary ideas from different sources, such as implementing what ideas they have observed experienced teachers using that they believe work well for pupils or using some online plenary ideas

- Asking the beginning teacher to plan the timings of the plenary as an essential part of their lesson planning to avoid cutting the plenary short to complete the lesson on time 
- Sharing some plenary ideas with them, for examples finishing the lesson by reintroducing the lesson starter and asking pupils to consolidate what they have (or not) learned in the lesson using lesson evaluation approaches such as exit passes (Part-three section of Table 6.3), using washing-line activity (see example in Chapter 11, ppxx), or asking pupils to write 'what went well' and 'what they (pupils) need support with' et cetera). Sharing and discussing how pupils' responses gained from the plenary activity can guide the planning for the next lesson

- Finally, discuss with the beginning teacher the benefits and drawbacks of: the planned plenary activity, the appropriateness of it, and its association with the key questions, learning outcomes and lesson starter.

In addition, it is possible to construct a lesson that has mini-plenaries that are introduced at different times in the lesson. You can, for example, ask the beginning teacher to use question and answer (Q\&A) styled plenary to assess pupils (some example questions in Table 6.5 can be revisited during plenary time). These Q\&A periods could also include planning for extension questions (such as examination-style questions).

\section{Participatory appropriation plane}

At the start of this stage, a beginning science teacher should be independently planning and teaching full lessons. During this stage, they should be demonstrating a deeper level of reflection, which requires high support from you, especially to plan for differentiation and to produce long-term learning plans for pupils. Some suggestions for mentoring based on differentiation are presented below:

1.Planning for differentiation

To further reflect on the intended learning outcome, it is beneficial that a beginning teacher is aware of the different competency levels of pupils in the class. A beginning teacher can observe pupils' different individual competence levels by collecting evidence, such as pupil's written and/or verbal accounts, examination/test results, and classroom engagement with peers and material resources from all the pupils. You could perhaps ask the beginning teacher to focus on two or three pupils (ideally from the same class/year group), who they believe require differing learning support. Once some pupils are selected, you can then assist the beginning 
teacher in planning appropriate learning outcomes according to the needs of those selected pupils.

Table 6.4 can be used to record information about the pupils and how their data can be used to adopt the planned learning outcomes or to adapt them according to the learning needs of these pupils. In the first column of Table 6.4 initials of the selected pupils are inserted. Type of evidence (such as test results, field notes based on the selected pupil's behaviour with other pupils' et cetera) is included in the second column. Observations gained from the evidence is included in the third column, then some or all the learning outcomes in the fourth column and finally, the in last column some points from discussions with you regarding the competence levels of the selected pupils.

Table 6.4 Planning tasks according to pupil's different competence levels.

\begin{tabular}{|l|l|l|l|l|}
\hline Name initials & $\begin{array}{c}\text { Evidence } \\
\text { type }\end{array}$ & My observation & Learning outcomes & $\begin{array}{c}\text { Discussion with the } \\
\text { mentor }\end{array}$ \\
\hline Pupil 1: & & & & \\
\hline Pupil 2: & & & & \\
\hline Pupil 3: & & & & \\
\hline
\end{tabular}

2.Planning for differentiated questions

In supporting a beginning teacher in a pre-lesson discussion to plan a range of questions for pupils, you need to ensure that these questions address all expected learning outcomes for all pupils. This means that some questions could be targeted for the whole class, while other questions could only be for some pupils. As an extension to Table 6.1, Table 6.5 can be shared with the beginning teacher to initiate forming closed questions (which usually ask pupils for one-word answers or facts), guided questions (which ask pupils to think critically using some visible or hidden clues in the questions) and open-ended questions (which require pupils to analyse and self-evaluate their knowledge and skills) to promote pupils learning. Some examples of closed, guided and open-ended questions along with the learning outcomes for the example of 'electricity' are given in Table 6.5. Chapter 16 page $\mathrm{xx}$ differentiates the three types of questioning (note: it refers to closed-ended questions as 'closed-guided', guided as 'closed- 
convergent' and open-ended questions as 'open-divergent'). Task 6.7 asks you to support the beginning teacher to plan for differentiated questions.

\section{Task 6.7 Mentoring to support planning for differentiated questions}

Encourage a beginning teacher to complete Table 6.5. In completing the table:

- Support the beginning teacher to complete the last three columns (closed, guided, open) with different types of questions they could ask pupils. Some example questions are presented in the table.

- Ask the beginning teacher to signpost these closed, guided and open questions in relation to the potential ways they will be asked and answered. For example, signpost questions as Classroom Verbal (CV) if the beginning teacher is planning to ask some planned questions verbally in the classroom, or Classroom Written (CW) for questions which pupils will be asked to give written answers to either in the classroom or homework written (HW)

- Instruct the beginning teacher to signpost initials of those pupils who will be individually approached to answer some particular questions

- Discuss the beginning teacher's justifications behind the signposting and suggest alternative strategies (if required) before these questions are practised in the classroom.

[You could use a different unit of work to complete Table 6.5]. 
Table 6.5 Using a range of questions to target the particular needs.

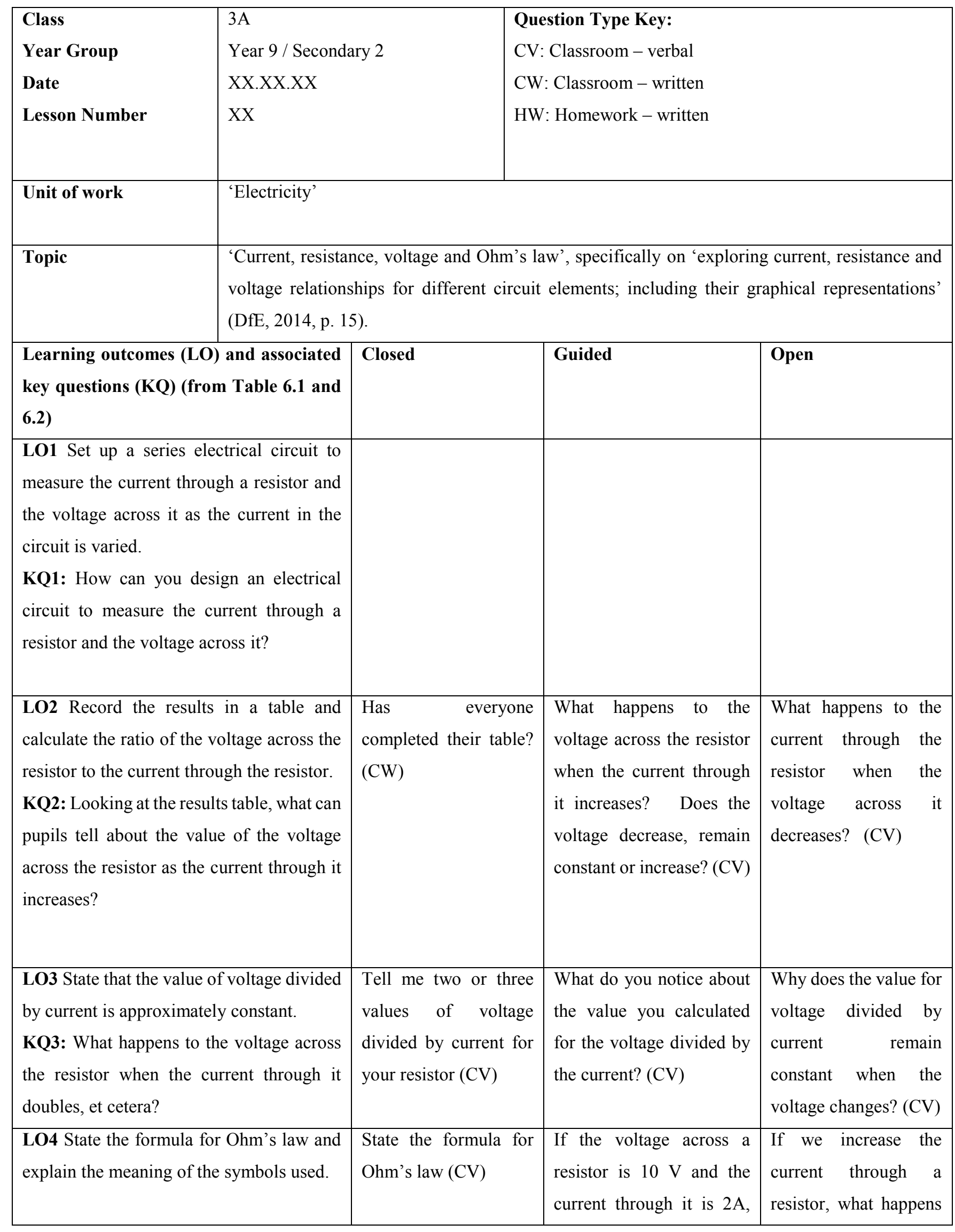




\begin{tabular}{|c|c|c|}
\hline $\begin{array}{l}\text { KQ4/6: Describe the relationship between } \\
\text { the current through the resistor and the } \\
\text { voltage across it? What is the relationship } \\
\text { between the voltage across a resistor and } \\
\text { the current through it? }\end{array}$ & $\begin{array}{l}\text { what is the resistance of } \\
\text { the resistor? }(\mathrm{CW})\end{array}$ & $\begin{array}{l}\text { to the voltage across it? } \\
\text { Explain why this } \\
\text { happens? }(\mathrm{CV})\end{array}$ \\
\hline $\begin{array}{l}\text { LO5 plot a graph of voltage against } \\
\text { current. } \\
\text { KQ5: What sort of line can pupils draw on } \\
\text { the graph? (Straight line or curve of best } \\
\text { fit). }\end{array}$ & & \\
\hline $\begin{array}{l}\text { LO6 state that the resultant straight-line } \\
\text { graph shows that the voltage across a } \\
\text { resistor is directly proportional to the } \\
\text { current through it. } \\
\text { KQ6/4: What is the relationship between } \\
\text { the current and the voltage for a resistor? } \\
\text { What is the relationship between the } \\
\text { voltage across a resistor and the current } \\
\text { through it? }\end{array}$ & & \\
\hline
\end{tabular}

3.Planning for differentiated tasks for the same activity

You also need to guide a beginning teacher in planning tasks for pupils which are supportive, yet at the same time challenging. You could encourage them to plan tasks for all the pupils but keep them open-ended to give opportunities to pupils to take different routes to accomplish some learning outcomes (Bartlett, 2016). At this plane of development, it is important that the beginning teacher sees differentiation as a way to enable all pupils to learn as an integral part of the planning process rather than an "add on" after the lesson has been planned. Integrating differentiation into planning is an effective way to include all pupils in the lesson. For example, in a lesson plan on 'electricity' (Table 6.3), all pupils will be able to carry out the practical work, possibly with some support. Most pupils will see, possibly with some guidance from the teacher, that roughly speaking as the current through the resistor doubles, so does the resistance across it. Some pupils may suggest calculating the value of the voltage divided by the current for their resistor, but all pupils can carry out this calculation using a calculator. Some pupils may have the skills to plot a graph of the results and know that the resulting straight-line graph shows that the ratio of voltage divided by the current is constant. Then, all groups of pupils can 
be included in the discussion about the formula for Ohm's law: voltage equals current times resistance. This all, most and some examples to include differentiation linking to the five learning outcomes can be seen in Table 6.3.

Planning for differentiated tasks could be a challenge for a beginning teacher, therefore initially at this participatory appropriation plane of development you could co-plan tasks with them and then jointly reflect on the impact of differentiated planning on teaching. While coplanning with the beginning teacher, you could ask them to answer questions indicated in Table 6.6. A useful mentoring strategy here is for you to take the lead in planning the differentiated tasks initially and gradually letting the beginning teacher take more responsibility for incorporating differentiation in lessons. As the beginning teacher gains more experience, they could plan the lesson for you to teach. Sharing and swapping the planning and teaching roles in this way, especially at the participatory appropriation plane, is helpful for a beginning teacher's development.

Table 6.6 Planning differentiated tasks.

\begin{tabular}{|c|c|}
\hline \multicolumn{2}{|c|}{ In this box, identify and describe the planned activity/task: } \\
\hline $\begin{array}{c}\text { Questions } \\
\text { ('I' refers to a beginning teacher) }\end{array}$ & A beginning teacher's response \\
\hline $\begin{array}{l}\text { What } \operatorname{task}(\mathrm{s}) \text { would I change to } \\
\text { simplify this activity? }\end{array}$ & \\
\hline $\begin{array}{l}\text { What task(s) would I change to make } \\
\text { this activity more challenging? }\end{array}$ & \\
\hline $\begin{array}{l}\text { What roles would I assign to individual } \\
\text { pupils? }\end{array}$ & \\
\hline $\begin{array}{l}\text { How can I support all pupils to } \\
\text { complete the activity? }\end{array}$ & \\
\hline $\begin{array}{l}\text { How can I vary the questions to include } \\
\text { all the pupils? }\end{array}$ & \\
\hline $\begin{array}{l}\text { How can I support pupils to work with } \\
\text { peers and in teams? }\end{array}$ & \\
\hline Other questions to consider... & \\
\hline
\end{tabular}




\section{Long-term planning}

The next step for you is to support a beginning teacher in managing the transition in planning from individual lesson plans to long-term learning plans (i.e. interconnected multiple sequences of learning) for a specific unit of work or a combination of units of work. A longterm learning approach could support pupils' learning by adhering to the cognitive psychology perspective of learning as 'an alteration in long-term memory' (Sweller, 2005, p. 20). Given this definition, it stands to reason that planning pupils' learning should be focussed on making appropriate alterations to pupils' long-term memory through a series of lessons (Chapter 13). To support this, once the beginning teacher develops the ability to plan effective individual lessons focused on learning for all pupils, you could further support them in developing their planning for a sequence of lessons . Task 6.8 asks you to support a beginning teacher to develop a long-term plan based on a sequence of lessons using a unit of work and/or a combination of units of work. 


\section{Task 6.8 Long-term planning}

Undertake the following steps:

1. Ask the beginning teacher to accumulate individual lesson plans from the last fourto-six series of lessons taught to a particular class of pupils from a specific unit of work (such as forces) or a combination (such as energy and forces)

2. Next ask the beginning teacher to map common elements that these series of lessons present, such as:

- The overarching links

- The intended learning outcomes for the end of the sequence of lessons

- Some interlinking key scientific vocabularies

- The expected prior learning that is relevant to the unit of work

- Acknowledgements of common pre-conceptions/misconceptions and how to deal with them

- Types of assessment used across the sequence

- Resources and activities used across the sequence of learning.

3. Discuss the mapping of these lessons (obtained from a complete unit of work or a combination of two or three units of work) and offer the beginning teacher opportunities to develop it further for the next series of lessons

4. Finally, ask the beginning teacher to reflect on planning the long-term plans (encompassing a complete unit of work or a combination of two or three units of work), rather than individual lesson plans by answering the below questions:

- What does long-term planning of learning look like?

- Are individual lesson plans good evidence of planning for learning?

- What are the benefits and drawbacks to short and long-term planning (daily plans, weekly plans, monthly plans, half-term plans, and yearly plans)?

- Based on the beginning teacher's thoughts about the above three questions consider how they would facilitate a shift in planning for individual lesson plans to a long-term planning. 


\section{Summary and key points}

This chapter has explored how best to support a beginning teacher with lesson planning, highlighting:

- Self-reflection and mentoring strategies on lesson planning for pupils' long-term learning. The use of Kolb's (1984) experiential learning cycle to explore ways you can provide feedback and support a beginning teacher at different points in their journey and to grow as an autonomous teacher

- Involvement of experienced teachers to support the beginning teacher's lesson planning practices

- Ideas on how to support the beginning teacher in planning for learning outcomes, key questions, learning activities and associated tasks for a single lesson and how it can build further to incorporate differentiation to support learning progression for all pupils

- The notion that the beginning teacher needs to progress from planning single lessons to planning a sequence of lessons, encompassing a complete unit of work or a combination of two or three units of work, in order to account for the development of pupils' longterm learning expectations.

\section{Further resources}

Fautley, M. and Savage, J. (2013) Lesson Planning for Effective Learning. Maidenhead: McGraw-Hill Education.

Fautley and Savage provide an overview of the stages of the lesson planning process and encourage beginning teachers to reflect on their practice. This book also considers lesson planning in the wider context of teaching and learning. In particular, Chapter 6 considers a number of different metaphors for teaching which you can use to encourage a beginning teacher to develop their pedagogy and become better teachers.

Savage, J. (2015) Lesson Planning. Abingdon: Routledge.

This book puts learning at the heart of planning, with step-by-step guidance on how and why lessons should be planned. A valuable tool for mentors to use to support a beginning teacher to plan lessons because it links theory to practice and provides exemplars for short and intermediate planning. 


\section{Appendix 6.1 Handout for pupils investigating the relationship between the voltage}

across a resistor and the current through it.

Name

Class

Date

Title Investigating the relationship between the voltage across a resistor and the current through it

Aim To design an experiment to investigate the relationship between the voltage across a resistor and the current through it

Method We designed the following circuit to investigate the relationship between current and voltage for a resistor:

Results

\begin{tabular}{|l|l|l|l|}
\hline & & & \\
\hline & & & \\
\hline & & & \\
\hline & & & \\
\hline & & & \\
\hline & & & \\
\hline
\end{tabular}

If you have time, plot your results on a voltage-current graph.

\section{Conclusion}


